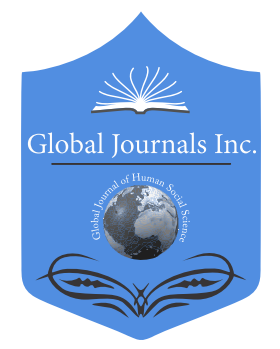

GLOBAL JOURNAL OF HUMAN-SOCIAL SCIENCE: A

ARTS \& HUMANITIES - PSYCHOLOGY

Volume 20 Issue 4 Version 1.0 Year 2020

Type: Double Blind Peer Reviewed International Research Journal

Publisher: Global Journals

Online ISSN: 2249-460x \& Print ISSN: 0975-587X

\title{
Social Support and Sex Role Orientation as Predictors of Quality of Life in Senior Citizens
}

By Yajvinder \& Dr. Anita Sharma

Himachal Pradesh University

Abstract- The present study was aimed to explore the relationship of social support and sex role orientation with quality of life in senior citizens. The sample comprised of 400 senior citizens with equal number of educated males and females (200 each). The analysis revealed that for the male's sample, social support explained the maximum variance (5\%) followed by femininity (4\%) in quality of life. In all, these variables have accounted for $9 \%$ of the variance. In female's sample, only social support has contributed (5\%) of variance. Further, t-test has revealed the superiority of males in masculinity, femininity and quality of life and female's superiority on social support.

Keywords: social support, sex-role orientation, quality of life, gender.

GJHSS-A Classification: FOR Code: 130205p

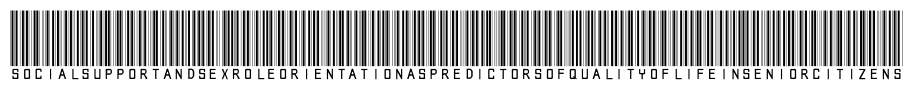

Strictly as per the compliance and regulations of:

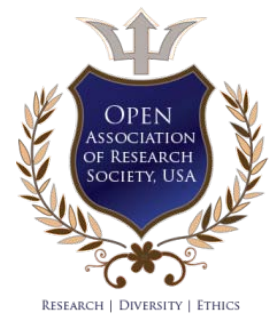

(C) 2020. Yajvinder \& Dr. Anita Sharma. This is a research/review paper, distributed under the terms of the Creative Commons Attribution-Noncommercial 3.0 Unported License http://creativecommons.org/licenses/by-nc/3.0/), permitting all non-commercial use, distribution, and reproduction in any medium, provided the original work is properly cited. 


\title{
Social Support and Sex Role Orientation as Predictors of Quality of Life in Senior Citizens
}

\author{
Yajvinder $^{\alpha}$ \& Dr. Anita Sharma ${ }^{\sigma}$
}

Abstract- The present study was aimed to explore the relationship of social support and sex role orientation with quality of life in senior citizens. The sample comprised of 400 senior citizens with equal number of educated males and females (200 each). The analysis revealed that for the male's sample, social support explained the maximum variance $(5 \%)$ followed by femininity (4\%) in quality of life. In all, these variables have accounted for $9 \%$ of the variance. In female's sample, only social support has contributed (5\%) of variance. Further, t-test has revealed the superiority of males in masculinity, femininity and quality of life and female's superiority on social support.

Keywords: social support, sex-role orientation, quality of life, gender.

\section{InTRODUCTION}

t's not enough to just be alive. Good quality of life is especially important for older adults who are dealing with chronic health conditions and major life changes. Life, as are many things, is often not always about quantity so much as it is about quality. Aging seniors often face losses in the quality of their lives well before they face the end of their days. In fact, having a positive view of life can help seniors have more energy, less stress, better appetite, and prevent cognitive decline.

Globally, quality of life among elderly is an important area of concern which reflects the health status and well-being of this population. Quality of life is affected by the many demanding situations and associated with aging related factors that are changing in health status, coping with new restrictions in life, identifying new roles, opportunities and available social support (Rayirala, Nallapaneni, Bhogaraju, \& Mandadi, 2016).

Social support may play a particular important role in maintaining health and decreasing susceptibility to illness among the elderly (Pilisuk \& Parks, 1988). Senior citizens with loss of social support have been observed to be at a higher mortality health risk (Silverstein \& Bengtson, 1991) and higher levels of psychological distress due to mistreatment (Comijs, Penninx, Knipscheer \& van Tilburg, 1999).

Social support is a tangible or an instrumental support which includes physical or financial assistance

Author a: Research Scholar, Department of Psychology, Himachal Pradesh University, Summer Hill, Shimla-5.

e-mail: yajvinderbhandari055@gmail.com

Author o: Professor, Department of Psychology, Himachal Pradesh University, Summer Hill, Shimla-5. e-mail: anitahpu@gmail.com and emotional support from family, friends and neighbours which leads an individual to feel a sense of belonging (Tomaka, Thompson \& Palacios, 2006).

Loss of social support harms the quality of life (Baxter, Shetterly, Eby, Mason, Cortese \& Hamman, 1998). In a social milieu where family networks continue to be the major source of psychosocial support and deep-rooted culture norms and perception regarding the family, although apparently dwindling in the near past, the role of the family as the crucial source of social support for the elderly people assumes a greater significance. Thus, effective family support is a key component of the overall well-being of the elderly people (Naing, Nanthamongkolchai \& Munsawaengsub, 2010). In the elderly, social aspects involve social networks and social support. Better social networks, which are linkages among group of known people, and better social support lead to better health outcome and well-being. Relationships protect from insecurity and psychosocial risk and hence are important for a good quality of life (Cavallero, Morino-Abbele, \& Bertocci, 2007 \& Chong, Ng, Woo, \& Kwan, 2006).

Another important factor which plays a vital role in determining ones' quality of life is sex role orientation. Gender roles are usually centered on conceptions of femininity and masculinity. Individuals who score high on masculinity and low on femininity are classified as masculine. Similarly, individuals are classified as feminine if they score high on femininity and low on masculinity.

Masculine men are characterized by a greater tendency to perform health behavior, which lead them to a faster recovery after myocardial infarction (Batlis \& Small, 1982; Radley et al., 2000). Moreover, people with androgynous (i.e., mixed feminine and masculine) type of psychological gender rate themselves as healthier than people with other types of psychological gender (Batlis \& Small, 1982; Gale-Ross, Baird, \& Towson, 2009). Other studies report that high femininity predicts better outcome among men after myocardial infarction (Barrett-Connor, 2007, Helgeson, 1991; Hunt, Lewars, Emslie, \& Batty, 2007).

Underlying the importance of these factors, the present study is aimed at testing these formulations to understand the exact variance contributed by the sex role orientation and social support on quality of life in senior citizens. 


\section{METHOD}

\section{a) Sample}

A sample of the study comprised of 400 educated senior citizens with equal number of males and females (200 each) above 60 years of age group from different districts of Himachal Pradesh. The sample was selected on the basis of purposive convenient sampling technique.

\section{b) Design}

A correlational design was used to see the association between social support and sex-role orientation with quality of life. Regression analysis was computed separately for both the genders (males and females) to find out the best set of predictors of quality of life. t-test was also computed to find out the significance of differences on all the predictor variables and criterion variable.

\section{c) Too/s}

Social Support (Zimet, Dahlem, Zimet, \& Farley, 1988): Social support was measured with the Multidimensional Scale of Perceived Social Support. The MSPSS was designed to assess the perceived adequacy of social support from family, friends, and significant others (Zimet, Dahlem, Zimet, \& Farley, 1988). The MSPSS comprises of 12 items, four items in each of three subscales. Items for each source are scored on a seven-point Likert-type scale ranging from "very strongly disagree" (1) to "very strongly agree" (7). Each set of items provides an index of support from each source. The subscale score for each respondent is computed by summing the ratings for each item for each support scale and then dividing the resulting total by 4 . For the total score, ratings are summed and divided by 12 . Total and subscale scores range from 1 to 7 , with high scores indicating a heightened perception of available social support. For this study, the focus was on the total score.

Bem Sex Role Inventory (Bem, 1974): This scale is used to measure sex-role orientation. This scale treats masculinity/femininity as two orthogonal dimensions rather than as two ends of a single dimension (Bem \& Watson, 1976). It consists of sixty personality characteristics. Twenty of the characteristics are stereotypically feminine e.g., affectionate, gentle, understanding, sensitive to needs of others etc. and twenty are stereotypically masculine e.g., ambitious, self-reliant, independent, assertive etc. The BSRI also contains twenty characteristics that serve as buffer items e.g., truthful, happy, conceited etc. When taking the $\mathrm{BSRI}$, an individual is asked to indicate on a 7 point scale, how well each of the 60 characteristics describes herself or himself. The scale ranges from 1 (never or almost never true) to 7 (always or almost always true) and is labeled at each point.
WHOQOL-BREF WHOQOL, 1996): The data were collected with a questionnaire named WHOQOL-BREF (1996) conceptualized by Alisen Harper. The 26 items WHOQOL-BREF consist of two overall items measuring general quality of life and health conditions and 24 items that are universally adopted for the WHOQOL-BREF in four domains are health, psychological well being, social relationship and environment. Each item was rated on a 5 point likert scale (higher score denotes higher quality of life).

\section{Results}

Results indicate that quality of life of male senior citizens is significantly and positively correlated with social support, $r=.329^{* *}(p<.01)$ and femininity $r=.246^{\star *}(p<.01)$ and in female senior citizens, only social support, $r=.457^{\star *}(p<.01)$ has turned out to be the significant correlate of quality of life (see figure 1). In the male's sample, when independent variables were entered in the regression model with quality of life, social support emerged as the best predictor accounting for $5 \%$ of variance. A significant increase of $4 \%$ was observed in $\mathrm{R}^{2}$ when it was entered along with femininity accounting for $9 \%$ of the total variance in quality of life (see table 1). Whereas in female's sample, when independent variables were entered in the regression model with quality of life, social support emerged as the only best predictor accounting for $5 \%$ of variance in quality of life (see table 2). Results have further shown the superiority of males on quality of life with $t=1.98$, $p<.05$, masculinity with $t=1.92, p<.05$ and femininity with $t=1.68, p<.05$ to that of females and female's superiority on social support, $t=6.82, p<.01$ to that of males.

\section{Discussion}

In the regression analysis of both the samples, social support has come up as the best and common predictor of quality of life. Social support is the emotional and practical support received from family and friends (Ajrouch, Blandon \& Antonucci, 2005). Support from family and friends help overcome Ioneliness and health problems related to aging. Family relations are important aspect of healthy aging among the elderly and the lack of social support and family and friends may likely cause the individual to perceive old age as uncertain and insecure (Khan \& Tamir, 2014). Social support is the particular source of happiness and subjective well-being of senior citizens (Sharma \& Malhotra, 2010). Social support is important for the quality of life of senior citizens, as it gives one a feeling of being loved, cared for, and esteemed, valued and belonging to a network of communication and mutual belongingness (Singh, 2005; Sharma, 2011). Several studies showed that family support and social relationship are positively related to a better quality of life 
(Sharma, 2011; Siedlecki, Salthouse, Oishi \& Jeswani, 2014; Kumcagiz \& Sahin, 2017). The reason being that elderly people who receive sufficient support from family, friends tend to develop positive attitudes and behaviours, improve social skills which in turn have a positive effect on quality of life. Moreover, social support independently affects mood and well-being in the elderly and risk of depression increases with the severity of loneliness (Golden, Conroy, Bruce, Denihan, Greene, Kirby, \& Lawlor, 2009). Another study found that older adults who had poorer social network had also worse quality of life (Garcia, Banegas, \& Paerez-Regadera, 2005). Kahan, Hessling, \& Russell (2003) found that relationship between perceived social support and psychological well-being were quite strong. Moreover, increased socialization is advantageous for emotional health and overall well-being. Femininity is another important factor that has predicted the quality of life in male senior citizens. A feminine individual is one who endorses more feminine characteristics such as gentleness, patience, kindness and concern for interpersonal relationship and emotional expression. Males with more femininity traits exhibit higher levels of internal health control and higher levels of psychological well-being (Matud, Garcia, \& Fortes, 2019; Pudrovska, 2015; Priess, Lindberg, \& Hyde, 2009).

The results further revealed the superiority of male senior citizens on quality of life, masculinity and femininity to that of females who have scored significantly higher on social support. Male senior citizens reported significantly better quality of life than females. The reason being that males are more committed, take the challenges willingly and control their emotions which strengthen their physical and mental power thereby improving quality of life and overall subjective well-being (Singh, 2005; Sharma, 2011). Men have less health problem and better quality of life in comparison to women. This may be related with the culture that men have dominance in traditional Indian family structure. They have better social life, economic freedom and less responsibility (Deshmukh, Dangre, Rajendran \& Kumar, 2015). On masculinity, males have scored significantly higher indicating stereotypical gender differences. Men endorsed masculinity traits to a greater extent than did women. On femininity, males have scored significantly higher because they are trying to show that they are more kind-hearted and care for others which is desirable in society and they think that endorsing feminine traits will make them better character as men (Strough, Leszczynski, Neely, Flinn \& Margrett, 2007). On social support, females have scored significantly higher pointing to the fact that females participate in more domestic activities and keep busy themselves in social activities and hence get more social support which enhances their quality of life and overall well-being (Sharma, 1995; Sharma, 2011). Females tend to report larger social networks than males and turn to others for emotional support in stressful circumstances (Taylor, Klein, Lewis, Gruenewald, Gurung, \& Updegraff, 2000). According to Kessler, McLeod and Wethington (1985) women provide more emotional support to both men and women and they get more help in return. Moreover, women are generally more empathetic and expressive than men (Bell, 1981).

\section{Conclusion}

In a nutshell, social support has been found to be the common significant predictor of quality of life in senior citizens (males and females). Moreover, significant gender differences have been found on quality of life, masculinity, femininity and social support. The papers' findings point to the need to encourage both the genders to imbibe each other's characteristics for proper adjustment and better quality of life. Further, senior citizens must be encouraged to spend more time with family and friends, to actively participate in collective activities and actively talk to family members or friends when encountering troubles or are confused with something. This way their quality of life may be enhanced.

\section{References Références Referencias}

1. Ajrouch, K.J., Blandon, A.Y., \& Antonucci, T. (2005). Social networks among men and women: the effects of age and socio-economic status. The Journal of Gerontology, 60(6), 311-317.

2. Barrett-Connor, E. (2007). Comentry: Masculinity, femininity and heart disease. International Journal of Epidemiology, 36(3), 621-622.

3. Batlis, N., \& Small, A. (1982). Sex roles and type A behaviour. Journal of Clinical Psychology, 38(2), 315-316.

4. Baxter, J., Shetterly, S.M., Eby, C., Mason, L., Cortese, C.F., \& Hamman, R.F. (1998). Social network factors associated with perceived quality of life. The San Luis Valley Health and Aging Study. Journal of Aging and Health, 10(3), 287-310.

5. Bell, R.R. (1981). Friendship of women and men. Psychology of Women Quarterly, 5(3), 402-417.

6. Bem, S. (1974). The Measurement of Psychological Androgyny. Journal of Consulting and Clinical Psychology, 42(2), 155-162

7. Cavallero, P., Morino-Abbele, F., \& Bertocci, B. (2007). The social relations of the elderly. Archives of Gerontology and Geriatrics, 44(1), 97-100.

8. Chong, AM-L., Ng, S.H., Woo J., \& Kwan, AY-H. (2006). Positive aging: the views of middle-aged and older adults in Hong Kong. Aging and Society, 26 (2), 243-249.

9. Comijs, H.C., Penninx, B.W., Knipscheer. K.P., \& Van Tilburg, W. (1999). Psychological distress in victims of elder mistreatment: the effects of social 
support and coping. Journal of Gerontology, 54(4), 240-245.

10. Deshmukh, P.R., Dangre, A.R., Rajendran, K.P., \& Kumar, S. (2015) Role of social, cultural and economic capitals in perceived quality of life among old age people in Kerala, India. Indian Journal of Palliative Care, 21(1), 39-44.

11. Gale-Ross, R., Baird, A., \& Towson, S. (2009). Gender role, life satisfaction, and wellness: Androgyny in a Southwestern Ontario sample. Canadian Journal of Aging, 28(2), 135-146.

12. Garcia, E.L., Banegas, J.R., \& Paerez-Regadera, A.G. (2005). Social network and health-related quality of life in older adults: a population based study in Spain. Quality Life Research, 14(2), 511-520.

13. Golden, J., Conroy, R.M., Bruce, I., Denihan, A., Greene, E., Kirby, M., \& Lawlor, B.A. (2009). Loneliness, social support networks, mood and well-being in community dwelling elderly. International Journal of Geriatric Psychiatry, 24(7), 694-700.

14. Helgeson, V.S. (1991). The effects of masculinity and social support on recovery from myocardial infarction. Psychosomatic Medicine, 53(6), 621-633.

15. Hunt, K., Lewars, H., Emslie, C., \& Batty, D. (2007). Decreased risk of death from coronary heart disease amongst men with higher "femininity" scores: A general population cohort study. International Journal of Epidemiology, 36(3), 614-622.

16. Kahan, J.H., Hessling, R.M., \& Russell, D.W. (2003). Social support, health and well-being among the elderly: What is the role of negative affectivity? Personality and Individual Differences, 35(1), 5-17.

17. Kessler, R.C., McLeod, J.D., \& Wethington, E. (1985). The costs of caring: A perspective on the relationship between sex and psychological distress. In Social Support: Theory, Research and Applications, 24, 491-506.

18. Khan, A.R., \& Tahir, I. (2014). Influence of social factors to the quality of life of the elderly in Malaysia. Open Medicine Journal, 1(1), 29-35.

19. Kumcagiz, H., \& Sahin, C. (2017). The relationship between quality of life and social support among adolescents. ERPA. SHS Web of Conference. 37, 1-7.

20. Matud, M.P., Garcia, M.C., \& Fortes, D. (2019). Relevance of gender and social support in self-rated health and life satisfaction in elderly Spanish people. International Journal of Environment Research and Public Health, 16(15), 1-15.

21. Naing, M.M., Nanthamongkolchai, S., \& Munsawaengsub, C. (2010). Quality of life of the elderly people in Einme Township, Irrawaddy division, Mayanmar. Asian Journal Public Health, 1, 4-10.
22. Pilisuk, M., \& Parks, S.H. (1988). Caregiving: Where families need help. Social Work, 33(5), 436-440.

23. Priess, H.A., Lindberg, S.M., \& Hyde, J.S. (2009). Adolescent gender-role identity and mental health: gender intensification revisited. Child Development, 80(5), 1531-1544.

24. Pudrovska, T. (2015). Gender and health control beliefs among middle aged and older adults. Journal of Aging and Health, 27(7), 284-303.

25. Radley, A., Grovea, A., Wrightb, S., \& Thurstone, H. (2000). Gender-role identity after heart attack: Links with sex and subjective health status. Psychology and Health, 1, 123-133.

26. Rayirala, A., Nallapaneni, N.R., Bhogaraju, A., \& Mandadi, G.D. (2016). A cross sectional comparative study assessing the quality of life in elderly living in old age homes and community and association of various factors with quality of life in Telangana. Journal of Psychiatry, 2 (1), 48-53.

27. Sharma, A \& Malhotra, D.K. (2010). Psycho-Social predictors of happiness disposition in the genders. Journal of Indian Health Psychology, 4(2), 77-83.

28. Sharma, A. (2011). Subjective well-being of retired teachers: The role of psycho-social factors. International Journal of Psychological Studies, 3(1), 36-42.

29. Sharma, N. (1995). Influence of certain psychosocial factors on psychological well-being of retirees. Unpublished Doctoral Thesis, University of Madras, Chennai.

30. Siedlecki, K.L., Salthouse, T.A., Oishi, S., \& Jeswani, S. (2014). The relationship between social support and subjective well-being across age. Social Indicators Research, 117(2), 561-576.

31. Singh, S. (2005). Determinants of health of retirees. In Rajbir Singh, Amrita Yadav and Nav Rattan Sharma (Eds.), Health Psychology, New Delhi: Global Vision Publishing House.

32. Silverstein, M., \& Bengtson, V. L. (1991). Do close parent-child relations reduce the mortality risk of older parents? Journal of Health and Social Behavior, 32(4), 382-395.

33. Strought, J., Leszczynski, J.P., Neely, T.L., Flinn, J.A., \& Margrett, J. (2007). From adolescence to later adulthood: femininity, masculinity, and androgyny in six age groups. Sex Roles, 57(5-6), 385-396.

34. Taylor, S.E., Klein, L.C., Lewis, B.P., Gruenewald, T.L., Gurung, R.A.R., \& Updegraff, J.A. (2000). Biobehavioral responses to stress in females: Tendand-befriend, not fight-orflight. Psychological Review, 107, 411-429.

35. Tomaka, J., Thompson, S., \& Palacios, R. (2006). The relation of social isolation, loneliness, and social support to disease outcomes among the elderly. Journal of Aging Health, 18(3), 359-84. 
36. Zimet, G.D., Dahlem, N.W., Zimet, S.G., \& Farley, G.K. (1988). The multidimensional scale of perceived social support. Journal of Personality Assessment, 52(1), 30-41.

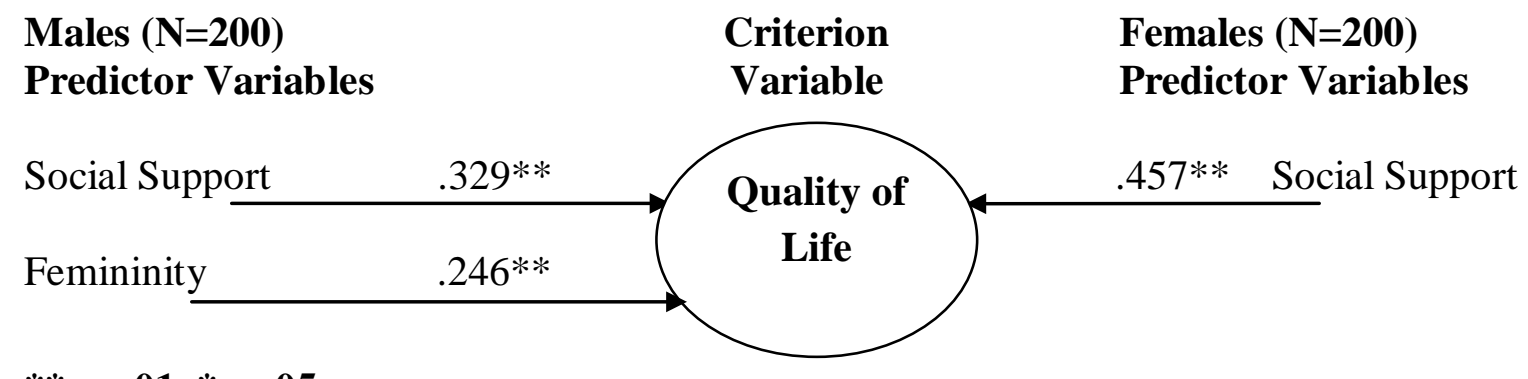

${ }^{* *} \mathbf{p}<.01, * \mathbf{p}<.05$

Figure I: Inter- correlations among Quality of Life, Social Support and Femininity in both the Genders (Males and Females, $\mathrm{N}=200$ )

Table 1: Stepwise Regression Analysis: Predictors of Quality of Life in Senior Citizens for Males' Sample (N=200)

\begin{tabular}{|c|c|c|c|c|c|c|c|c|}
\hline Predictors & Order of Entry & $\mathrm{r}$ & $\mathrm{R}$ & Beta Weight & $\mathrm{R}^{2}$ & $\mathrm{R}^{2}$ Change & $\mathrm{F}$ & Sig \\
\hline Social Support & 1 & $.329^{\star *}$ & .598 & .370 & .357 & .052 & 19.61 & .01 \\
\hline Femininity & 2 & $.246^{\star *}$ & .632 & .325 & .399 & .042 & 13.26 & .01 \\
\hline \multicolumn{7}{|c|}{ Total Variance Explained } \\
\hline
\end{tabular}

Table 2: Stepwise Regression Analysis: Predictors of Quality of Life in Senior Citizens for Females' Sample (N=200)

\begin{tabular}{|c|c|c|c|c|c|c|c|c|}
\hline Predictors & Order of Entry & $\mathrm{r}$ & $\mathrm{R}$ & Beta Weight & $\mathrm{R}^{2}$ & $\mathrm{R}^{2}$ Change & $\mathrm{F}$ & Sig \\
\hline Social Support & 1 & $.457^{\star \star}$ & .514 & .435 & .264 & .051 & 16.431 & .01 \\
\hline \multicolumn{8}{|c|}{ Total Variance Explained } \\
\hline
\end{tabular}

Table 3: Comparative Analysis of Male and Female Senior Citizens on Social Support, Femininity, Masculinity and Quality of Life.

\begin{tabular}{|c|c|c|c|c|c|c|}
\hline Variables & Gender & $\mathrm{N}$ & $\overline{\mathrm{X}}$ & SD & $\mathrm{t}$ & Sig. \\
\hline \multirow{2}{*}{ Quality of Life } & Males & 200 & 142.78 & 18.56 & \multirow{2}{*}{1.98} & \multirow[t]{2}{*}{.05} \\
\hline & Females & 200 & 139.02 & 20.19 & & \\
\hline \multirow{2}{*}{ Social Support } & Males & 200 & 43.45 & 6.60 & \multirow{2}{*}{6.82} & \multirow{2}{*}{.01} \\
\hline & Females & 200 & 48.10 & 7.03 & & \\
\hline \multirow{2}{*}{ Masculinity } & Males & 200 & 80.13 & 7.24 & \multirow{2}{*}{1.92} & \multirow{2}{*}{.05} \\
\hline & Females & 200 & 77.36 & 8.47 & & \\
\hline \multirow{2}{*}{ Femininity } & Males & 200 & 84.89 & 7.36 & \multirow{2}{*}{1.68} & \multirow{2}{*}{.05} \\
\hline & Females & 200 & 83.12 & 7.54 & & \\
\hline
\end{tabular}

